\title{
The training methods of scientific and technological innovation ability of college students specialty based on innovation and entrepreneurship project
}

\author{
Zhang Lanyong \\ College of Automation \\ Harbin Engineering University \\ Harbin China \\ zlyalf@sina.com
}

\author{
Liu Sheng \\ College of Automation \\ Harbin Engineering University \\ Harbin China \\ Liu.sch@163.com
}

\begin{abstract}
Based on the problem that the innovation of training process of automation specialty is not strong, this paper regards students' technological innovation projects, scientific and technological innovation incubator projects, and projects of promoting scientific and technological innovation as the carriers to enhance students' innovation awareness and innovative spirit, form the sharing and interaction of talent, technology and resource, and build scientific and technological innovation platform for college students through making more efforts to support college students for scientific and technological innovation. Through the establishment of comprehensive cooperation between enterprises and schools, schools and enterprises can realize complementary advantages, cooperation and win-win.
\end{abstract}

Keywords-scientific and technological innovation; college students; university-industry cooperation; enterprises universities researches

\section{PREFACE}

Since the implementation of the "excellent engineer plan" in 2010, it has played a positive role in promoting the undergraduate teaching level and carrying out the reform of undergraduate education mode. At the same time, the "excellent engineer plan" has also received strong support and response of the industrial sector, with the cooperation of various colleges and universities to carry out a variety of cooperation $^{[1]}$, greatly promoting the reform of the "excellent engineer plan" and the implementation of progress. According to the national ministry of education "the innovative laboratory supervision and management approach" and Heilongjiang Province on strengthening college students' entrepreneurship guidance and school on strengthening the cultivation of college students' innovation and entrepreneurship awareness and other related documents. This paper intends to promote the cultivation of the engineering practice ability of "excellence plan" through the research of scientific and technological innovation, combining itself with the specific circumstances of automation. This paper aims to study the establishment of college students' scientific and technological innovation platform and improve the scientific and technological innovation ability of students.

\section{THE BACKGROUND OF ESTABLISHMENT OF SCIENTIFIC AND TECHNOLOGICAL INNOVATION PLATFORM}

In fact, at home and abroad, there are already some existing university science and technology innovation platform systems $^{[2]}$. Among of them, some are relatively perfect, we can learn and study; and on the other hand, there are many existing problems, we need to pay attention to and improve, develop a set of scientific and technological innovation platform with our school's characteristics ${ }^{[3]}$.

\section{A. Foreign research orientation}

For foreign educational environment, whether it is from the aspect of open or from the aspect of supporting studying spirit of the students, they are far better than the domestic schools. In the field of undergraduate science and technology innovation platform, foreign colleges and universities, especially the science and engineering colleges ${ }^{[4]}$, have a certain degree on fixed technology innovation platform system. Including some famous universities abroad, for example, Harvard University has received good results in the process of running courses through the establishment of application and academic evaluation of interdisciplinary innovation agency platform.

\section{B. The current domestic situation}

Compared with other countries, under the traditional ideological restraints it has been the supremacy of examoriented education and scores until now. Our country's science and technology innovation is still in the slow development of long-term situation ${ }^{[5]}$. In this case, the construction of a science and technology innovation platform is impossible. With the lack of innovation ability of college students and the urgent need to study the new era of the country, on July 3,2004, the State Council forwarded the "2004-2010 National Science and Technology Platform Construction Program" developed jointly by the National Science and Technology Development and Reform Commission, Ministry of Education and Ministry of Finance. The construction of college science and technology platform will be the subject of the policy to improve the level of the policy, and it is foundation for all colleges and universities to carry out the relevant aspects of research. 
Our school's automation specialty influence is relatively large, its famous degree is relatively high in our country, and it has a certain influence in the world. Our school's automation specialty's construction started relatively early, the number of staff engaged in the research is large, and the influence is strong in industry. But because our school's research institute and the teaching unit have a certain separation, compared with the relative research, the investment in education is too small; the aspect of the teaching and scientific research has not formed a very good unification. There are many problems such as the lack of theory and practice, the lack of innovation ability. It is urgent to create better conditions and training talents mechanism to make students capable of more practical and innovative ability, and improve the practical ability and innovation ability of students, and train a large number of scarce innovative talents to meet the need of economic and social development.

In order to encourage the students to participate in scientific research activities ${ }^{[6]}$, to enhance students' interest and ability in scientific research and academic research, to cultivate innovative spirit and innovative consciousness, to improve students' academic level and comprehensive quality, to make college students contact truly scientific research, we should fully mobilize the enthusiasm of students to participate in scientific research and create a good atmosphere of academic research and build technological innovation platform of students ${ }^{[7]}$.

The platform of college students' scientific and technological innovation ability training regards students' technological innovation projects ${ }^{[8]}$, scientific and technological innovation incubator projects, and projects of promoting scientific and technological innovation as the carriers to enhance students' innovation awareness and innovative spirit, form the sharing and interaction of talent, technology and resource, and build scientific and technological innovation platform for college students through making more efforts to support college students for scientific and technological innovation ${ }^{[9]}$.

\section{THE ESTABLISHMENT PRINCIPLES OF PlATFORM OF COLlege STUdents' ABILITY OF SCIENTIFIC AND TECHNOLOGICAL INNOVATION}

The college related departments and the excellent teachers of the automation jointly set up the "college students science and technology innovation project" management committee, responsible for the management and supervision of scientific and technological innovation plan.

\section{A. The guiding principles}

It should take projects as carriers, take problems as orientation, and guides students to actively carry out various forms of scientific and technological innovation, and trains and improves their technological innovation ability. CMC should make a configuration of at least a professional instructor for each project team, and provide guidance for science and technology to promote the practice of science and technology promotion projects.

\section{B. The merit principles}

It should carry out a merit-based selection for projects with technical connotation and considerable promotional value. In addition to the promotion of basic scientific and technological knowledge and the project team's own research, it can also promote instructor's advanced scientific research.

\section{The principles of effectiveness}

It should select these projects that their economic, social and ecological effectiveness are more significant after the implementation of promotion.

\section{The student-centered principles}

We should choose these projects with a good technical basis, and the operation is relatively simple and it is easy to be accepted by promote regional. It must be suitable for college students. We should encourage students to bold technological innovation activities, but not over the pursuit of scientific and technological innovation activities, we should focus on the evaluation of scientific and technological innovation and the whole process of innovation.

\section{THE IMPLEMENTATION Of COLLEGE STUDENTS' SCIENTIFIC AND TECHNOLOGICAL INNOVATION ABILITY TRAINING PLATFORM}

It should take outstanding teachers as automation professional body and take the needs of school science park as traction to carry out scientific research and technological innovation to promote the formation of technology products and sales(or to participate in all types of internal and external science and technology competition).During the execution of the plan, when the students 'scientific research ability is trained, we can make students exposed to the company's operations, product marketing's whole process, and ultimately achieve the purpose of undergraduates' innovation and entrepreneurship and practical ability.

When the platform is in the implementation process, technical training and guidance are completed by the automation professional teachers. The required funds, space and material conditions are jointly funded by the automated specialty "Excellence plan" funding and college.

Specific implementation steps are as follows:

\section{A. Students individually apply it and the college preliminary audits it.}

The students technology innovation program is open to all students majoring automation with the following conditions:

- Positive thinking for progress, hard up.

- They must be two or three grade undergraduates with excellent grades in our college. They need to be capable of research ability, and can propose research with certain academic significance or practical value.

- They need certain research capacity, strong hands, and have the basic conditions of carrying out research capacity. 
- There is spare capacity, to ensure that they have the necessary time for the research work.

- Project leaders can complete research work within the stipulated period.

- Students can apply individually or form a team (in principle, the total number is no more than three) to apply. College needs organize some experts to conduct the trial.

\section{B. CMC reviews it.}

The students in the first instance selected by college need be reviewed by the administrative committee. The qualified students selected according to the individual will and the requirements of the administrative committee can join in different teams. They need to signed a guarantee "College Students' innovative plan guarantee" with the CMC and ensure timely the completion of the project.

\section{Project implementation}

CMC project leader is responsible for the study of the project, the organization and coordination of the project team ensuring to complete the task with certain quality and quantity.

It needs to make full use of automation engineering institute's technology, manpower and other resources, as well as advanced and mature technical results and the company's production conditions and markets to improve the institute's research capability, and change scientific research achievements into productive forces as soon as possible. The parties develop their own advantages, through a variety of comprehensive cooperation, to jointly promote the comprehensive technical cooperation, promote the formation of professional, industry mutual promotion and common development, and strive to achieve "school-enterprise cooperation, enterprises-universities win-win."

\section{The ReAlization Of StUdEnTS' SCIENTIFIC AND TECHNOLOGICAL INNOVATION ABILITY PLATFORM}

Automation specialty is based on the spirit of "complementary advantages, mutual benefit, cooperative innovation, and common development" principle, making full use of their respective colleges and enterprise resource platform, establishing strategic, compact all-round cooperative relations, forming the sharing of and interaction talent, technology, resources, strategic alliances innovative research cooperation, building a scientific and technological innovation platform for college students. Schools and enterprises realize complementary advantages cooperation and win-win through establishing a comprehensive research partnership with businesses.

After establishing students' science and technology innovation platform in 2011, it is open for undergraduate and graduate in school. It got an investment of 50,000 Yuan from national entrepreneurship training plans and platform four years of innovation and college spent about 50,000 Yuan, it also got about 100,000 self-financing Yuan. This innovative platform includes 10 teachers, more than 300 square meters of space, supporting 3 students' innovation teams, guiding students to write 30 patents, including 21 invention patents, received nine patents, guiding students to participate in the National Undergraduate Electronic Design Contest, Heilongjiang Province Undergraduate Electronic Design Contest, the "Siemens Cup" Industrial Automation Challenge, "the new US Cup" China University Biological networking innovation and entrepreneurship contest,"Renesas Cup" National Super MCU model car race, "Advantage Cup" college Things innovation Venture Competition, Harbin university student entrepreneurship competition, more than 10 events, a total of more than 150 students, which won 3 the National College Students Innovation and Entrepreneurship Training Program, three national prizes, two country third prizes, a the second Northeast Division Award, Heilongjiang Province,5 second prizes, 6 third prizes, Heilongjiang Province, Harbin City, a special award, a total of 24 winners. More than 11 eligible students walked through technological innovation achievements among 150 people.

The open management of innovation laboratory is realized in the platform construction. Laboratory management is the basis for the establishment and implementation of university students of technological innovation. In the case of safety, it should give full play to the ability of the laboratory, the opening hours of the week should be guaranteed not less than seven days and open daily more than 10 hours. At the same time, it also established the laboratory management system of students' self-management. It also has developed the ability of the students' self-management, and the development and operation of the laboratory are realized under the guidance of the teachers. On the foundation of University platform, it draws lessons from the foreign universities and college is managed and guided by the department in the school in charge of research and innovation and formed the three level management system consisting of teachers, students and school.

Through the construction of college students' innovation ability, the innovation ability and the spirit of the undergraduates have been improved. Supported by the national college students research training program, it has greatly improved the level of scientific research projects and assessment efforts through this innovative platform's whole reporting innovation projects and scientific research projects. Through the integration of some outstanding enterprises, it has established a complete "Academic - Innovation - R \& D Production - Return" virtuous circle system, which has accelerated the process of market oriented development of the research university, and provides a practical opportunity to develop a new type of talents with innovative ability.

\section{ACKNOWLEDGMENT}

The work was financed by Control Science and Engineering's Exploration and Practice (2011-16) in Heilongjiang Province, Exploration and Practice in University Teachers' Research and Achievement into Innovative Personnel Training's Practice Mechanism (JG2013010202) and Harbin Engineering University undergraduate education reform project Undergraduates' Technology Innovation and Small Business System's Research and Practice (JG2014BYB13), 
Planning Subject of Education Department of Heilongjiang Province (GBC1213103), Chinese Society of Academic Degree and Graduate Education Research Project(2015Y0403).

\section{REFERENCES}

[1] Wang Jie,Wang Duchun, Zhu Jieluo.Rely on the University's scientific research achievements to promote college students' venture.Journal of Harbin Institute of Technology(Social Science Edition)[J], 2010,12 (5):124 128

[2] Gao Guowu.Analysis of the current situation of scientific and technological achievements transformation of college students.Cooperative economy and technology[J],2010,8:18 20.

[3] Zhu Yonghua.Investigation and analysis of College Students' Entrepreneurship model.Journal of Wuhan Institute of Technology[J], 2010,6:124 128.
[4] Yang Fang.On the full promotion of entrepreneurship education.Innovation and entrepreneurship education[J], 2010,1:37 40.

[5] Ma Huimin.The cultivation system of scientific and technological innovation ability of college students.Education theory and practice[J], 2012,32 (36): 12 14.

[6] He Jianhong,Luo Hua.Research on the relationship between college students' entrepreneurship education and students' innovative spirit and entrepreneurial ability.Journal of Lanzhou Institute of Education[J], 2012,28 (9): 82 86.

[7] Li Zuchao,Nie Sa. Collaborative research and analysis and countermeasures.University of science and technology in China[J],2012, 8:24 25.

[8] Liu Renhuai."Political and industry cooperation" cooperation to promote collaborative innovation to a new level.University of science and technology in China[J],2012,7:7 8.

[9] Tang Yang.Thinking about collaborative innovation in colleges and universities.University of science and technology in China[J], 2012, 7:14 16. 